\title{
Structural Effects of the Antimicrobial Peptide Maculatin 1.1 on Supported Lipid Bilayers.
}

David I. Fernandez ${ }^{\mathrm{a}}$, Anton P. Le Brun ${ }^{\mathrm{b}}$, Tzong-Hsien Lee ${ }^{\mathrm{c}}$, Paramjit Bansal ${ }^{\mathrm{b}}$, Marie-Isabel Aguilar $^{\mathrm{c}}$, Michael James ${ }^{\mathrm{b}, \mathrm{d}}$ and Frances Separovic ${ }^{\mathrm{a}}$.

${ }^{a}$ School of Chemistry, Bio21 Institute, University of Melbourne, VIC 3010, Australia.

${ }^{\mathrm{b}}$ Bragg Institute, Australian Nuclear Science and Technology Organisation, Locked Bag 2001, Kirrawee DC, NSW 2232, Australia.

${ }^{c}$ Department of Biochemistry and Molecular Biology, Monash University, Clayton, VIC 3800, Australia.

${ }^{d}$ School of Chemistry, University of New South Wales, Kensington, NSW 2052, Australia.

Corresponding author:

pH: +61 $383447137 \quad$ fax: +61 $393478159 \quad$ email: $\underline{\text { fs@ unimelb.edu.au }}$

Key words: antimicrobial peptide; model membranes; peptide-lipid interaction; dual polarisation interferometry; neutron reflectometry 


\begin{abstract}
:
The interactions of the antimicrobial peptide, maculatin 1.1 (GLFGVLAKVAAHVVPAIAEHF-NH $\mathrm{N}_{2}$ ), with model phospholipid membranes were studied using dual polarisation interferometry and neutron reflectometry in dimyristoylphosphatidylcholine (DMPC) and mixed DMPC/dimyristoylphosphatidylglycerol (DMPG) supported lipid bilayers chosen to mimic eukaryotic and prokaryotic membranes, respectively. In DMPC bilayers maculatin displayed a concentration dependent binding and an increasing perturbation of bilayer order. By contrast, in mixed DMPC/DMPG bilayers, maculatin interacted more strongly and in a concentration dependent manner with retention of bilayer lipid order and structure, consistent with pore formation. These results emphasise the importance of membrane charge in mediating antimicrobial peptide activity and highlight the importance of using complementary methods of analysis in probing antimicrobial peptide mode of action.
\end{abstract}




\section{Introduction:}

The proliferation of bacteria resistant to modern arsenals of antibiotics poses an increasing challenge to researchers to develop novel antimicrobial agents that circumvent traditional pathways prone to developing resistance. One class of compounds, antimicrobial peptides (AMPs) that target differences in prokaryotic and eukaryotic membrane compositions, may provide useful leads to combat this challenge. Antimicrobial peptides are an abundant and diverse group of molecules used throughout nature to control and combat a broad range of microbes. While most traditional antibiotics have targeted critical biosynthetic pathways, antimicrobial peptides are commonly thought to target microbes primarily through nonreceptor mediated mechanisms that result in the disruption of microbial membranes. Two general hypotheses have been suggested to explain their mode of action, membrane binding and permeabilisation in a detergent like manner or peptide insertion and subsequent transmembrane pore formation (Oren and Shai 1999; Shai 1999; Shai and Oren 2001; Yang et al. 2001).

Maculatin 1.1 (GLFGVLAKVAAHVVPAIAEHF- $\mathrm{NH}_{2}$ ) is a cationic AMP isolated from the skin secretions of the frog species Litoria genimaculata (Rozek et al. 1998). Maculatin 1.1 is active towards numerous mainly Gram positive bacteria (Boland and Separovic 2006; Chia et al. 2000; Fernandez et al. 2009; Niidome et al. 2004) as well as possessing anti-tumour (Brinkworth and Bowie 2003) and anti-viral activity (VanCompernolle et al. 2005). Maculatin interacts with model membranes composed of zwitterionic dimyristoylphosphatidylcholine (DMPC) and mixed DMPC/dimyristoylphosphatidylglycerol (DMPG) bilayers with a higher affinity for the anionic membrane (Seto et al. 2007), which reflects the typical higher anionic lipid content within bacterial membranes. Previous studies conducted report that the peptide likely exerts its mode of action through a probable pore formation mechanism (Ambroggio et al. 2005; Boland and Separovic 2006; Chia et al. 2002; 
Gehman et al. 2008; Mechler et al. 2007). While these studies have captured valuable information towards the peptides overall mode of action, further information is needed to fully elucidate the mechanism particularly in terms of the change in membrane structure during binding and disruption. In this study we have used two complementary techniques, dual polarisation interferometry (DPI) and neutron reflectometry (NR) to study the temporal structural changes in bilayer properties caused by maculatin 1.1 and to obtain detailed information on spatial changes in lipid distribution within the bilayer.

\section{Materials and Methods}

Liposome preparation for Dual Polarisation Interferometry

1,2-dimyristoyl-sn-glycero-3-phosphocholine (DMPC) and 1,2-dimyristoyl-sn-glycero-3[phospho-rac-(1-glycerol)] (DMPG) were purchased from Avanti polar lipids (Alabaster, AL, USA) and used without further purification. Lipid stock solutions were prepared in organic solvent $\left(1: 1 \mathrm{CHCl}_{3}: \mathrm{MeOH}\right)$ and used to prepare pure DMPC and mixed DMPC/DMPG (4:1 molar ratio) thin films on clean Pyrex test tubes. The organic solvent was removed under a stream of $\mathrm{N}_{2}$ gas and placed under a high vacuum overnight to remove trace amounts of solvent. Thin lipid films were hydrated to $1 \mathrm{mM}$ lipid concentration with $10 \mathrm{mM}$ MOPS (3(N-morpholino) propanesulfonic acid), $150 \mathrm{mM} \mathrm{NaCl} \mathrm{pH} \mathrm{7.0,} \mathrm{buffer} \mathrm{solution} \mathrm{at} 37{ }^{\circ} \mathrm{C}$ for 1 hr with constant vortexing. The hydrated lipid suspension was sonicated in a water bath for $\sim 30 \mathrm{~min}$ at $37^{\circ} \mathrm{C}$. Generally, the lipid suspension became clear within $\sim 20 \mathrm{~min}$. The lipid solutions were extruded before use through $50 \mathrm{~nm}$ polycarbonate membranes (19 times) using an Avestin Liposfast extruder (Avestin, ON, Canada).

Deposition of unilamellar supported lipid bilayer on planar silicon oxynitride sensor chips 
Planar supported lipid bilayers (SLB) were prepared via in situ adsorption of liposomes to a silicon oxynitride waveguide sensor chip. An unmodified FB80 AnaChip (Farfield Group, UK) with dimensions $24 \times 6 \mathrm{~mm}$, was clamped inside a dual zone temperature controlled housing. The temperature was controlled to within $0.005^{\circ} \mathrm{C}$ using a Peltier system. A $100 \mu \mathrm{m}$ thick fluorosilicon gasket, containing two slots $\left(17 \times 1 \mathrm{~mm}^{2}\right)$ which provide two separate 1.7 $\mu \mathrm{L}$ microfluidic channels, was clamped over the sensing waveguide. A critical factor in producing lipid bilayers in a reproducible manner is ensuring the chip surface is stringently clean. To condition new FB80 waveguide chips and to clean between experiments, the surface was treated with consecutive injections of $10 \%$ Hellmanex II, $2 \%$ sodium dodecyl sulfate and absolute ethanol. Following chip cleaning, the optical properties of the chip surface were calibrated at $20{ }^{\circ} \mathrm{C}$ using consecutive injections of $80 \%$ ethanol (w/w) and $\mathrm{H}_{2} \mathrm{O}$ followed by calibration of the bulk buffer at 20 and $30{ }^{\circ} \mathrm{C}$. The bulk buffer solution, $10 \mathrm{mM}$ MOPS, $150 \mathrm{mM} \mathrm{NaCl}, \mathrm{pH} 7.0$ was used as the flow media throughout all experimental steps and all solutions were degassed prior to use. Flow rate during experiments was controlled using a Harvard Apparatus PHD2000 programmable syringe pump. Immediately prior to lipid bilayer formation, the temperature of the system was set to $28{ }^{\circ} \mathrm{C}$ and allowed to equilibrate. The previously prepared lipid stock suspension was extruded at this stage and diluted to $0.1 \mathrm{mg} / \mathrm{mL}$ with further MOPS buffer that contained $1 \mathrm{mM} \mathrm{CaCl}_{2}$.

The liposome solutions of DMPC and mixed DMPC/DMPG (4:1 molar ratio) were then injected for 10 minutes at a flow rate of $20 \mu \mathrm{L} / \mathrm{min}$. Immediately following liposome injection, further bulk buffer containing $1 \mathrm{mM} \mathrm{CaCl}_{2}$ was injected $(200 \mu \mathrm{L}$ at $20 \mu \mathrm{L} / \mathrm{min})$ for 10 minutes to stabilise the supported lipid bilayer. The adsorbed bilayer was allowed to equilibrate for a further 20 minutes under running buffer until a stable baseline had been achieved. Following this step, the temperature of the system was set to $30^{\circ} \mathrm{C}$ and the system allowed to further equilibrate before the peptide addition steps. 
Maculatin 1.1 was purchased from Mimotopes (Melbourne, Australia) at a purity of $>95 \%$ and used without further purification. Maculatin 1.1 was prepared at concentrations of 1, 2, 5, 10 and $20 \mu \mathrm{M}$ in the running buffer (10 mM MOPS, $150 \mathrm{mM} \mathrm{NaCl} \mathrm{pH} 7.0$ ). $160 \mu \mathrm{L}$ of each peptide concentration was injected sequentially onto the SLB in increasing concentrations at a flow rate of $40 \mu \mathrm{L} / \mathrm{min}$ with a total of 30 minutes equilibration time between injections.

\section{Dual polarisation interferometry}

Dual polarisation interferometry is an analytical technique that allows the study of thin films using dual optical waveguide interferometry (Terry et al. 2006; Mashaghi et al. 2008). DPI makes use of dual orthogonal polarisations of light passing through a sensing waveguide to measure several optical-geometric properties of an adsorbed material such as refractive index, density, thickness, mass and birefringence in real time.

Data acquisition was carried out using AnaLight200 version 2.1.0 software and analysed using AnaLight Explorer proprietary software as previously described (Lee et al. 2010b). The values of refractive index (n) and thickness (d) of an adsorbed isotropic single layer are determined by fitting the measured phase changes in the transverse electric $\left(\mathrm{T}_{\mathrm{E}}\right)$ and transverse magnetic $\left(\mathrm{T}_{\mathrm{M}}\right)$ waveguide modes. The non-random orientation of lipid molecules in a bilayer creates an anisotropic system with a uniaxial optical axis containing two principle refractive indices; the extraordinary refractive index $\left(\mathrm{n}_{\mathrm{e}}\right.$, the refractive index perpendicular to the surface) and the ordinary refractive index $\left(\mathrm{n}_{\mathrm{o}}\right.$, parallel to the surface). The difference between $n_{e}$ and $n_{o}$ (optical anisotropy) for a lipid film is defined as the birefringence $\left(\Delta n_{f}\right)$ which is calculated by the difference between the two effective refractive indices measured by the $T_{M}$ and $T_{E}$ waveguide modes $\left(n_{T M}\right.$ and $\left.n_{T E}\right)$. The molecular order of the bilayer is proportional to the birefringence value with high $\Delta \mathrm{n}_{\mathrm{f}}$ values for a highly aligned lipid bilayer, 
while a lower $\Delta \mathrm{n}_{\mathrm{f}}$ value represents a more randomly ordered bilayer. The effective bilayer birefringence may only be determined by fixing either the thickness or refractive index (RI) of the adsorbed layer and assuming uniform layer coverage. For the purposes of the present study, a constant isotropic RI (1.47) was assumed for the lipid bilayer throughout the peptidemembrane interaction. In order to calculate the adsorbed mass of the bilayer, the isotropic refractive index, $\mathrm{n}_{\text {iso }}$ must first be calculated using

$$
\mathrm{n}_{\mathrm{iso}}=\left[\left(\mathrm{n}_{\mathrm{TM}}{ }^{2}+2 \mathrm{n}_{\mathrm{TE}}{ }^{2}\right) / 3\right]^{1 / 2}
$$

The de Feijter equation may then be used to calculate the mass of the adsorbed layer (De Feijter et al. 1978). The mass of the adsorbed lipid bilayer, $\mathrm{m}_{\text {lipid }}$, and that of the bound peptide, $\mathrm{m}_{\text {peptide, }}$ were calculated as follows

$$
\begin{aligned}
& \mathrm{m}_{\text {lipid }}=d\left(\mathrm{n}_{\text {iso }}-\mathrm{n}_{\text {buffer }}\right) /(\mathrm{dn} / \mathrm{dc})_{\text {lipid }} \\
& \mathrm{m}_{\text {peptide }}=d\left(\mathrm{n}_{\text {iso }}-\mathrm{n}_{\text {buffer }}\right) /(\mathrm{dn} / \mathrm{dc})_{\text {peptide }}
\end{aligned}
$$

where $d$ is the resolved thickness of the adlayer, $\mathrm{n}_{\text {buffer }}$ is the experimentally determined refractive index of the MOPS buffer used in these experiments and was $n_{\text {buffer }}=1.3335$ at 30 ${ }^{\circ} \mathrm{C}$ and $\mathrm{dn} / \mathrm{dc}$ is the refractive index increment of the adlayer. The de Feijter formula assumes a constant $\mathrm{dn} / \mathrm{dc}$ value and for the current analysis the values of $0.135 \mathrm{~mL} / \mathrm{g}$ and $0.182 \mathrm{~mL} / \mathrm{g}$ were used for lipids and peptides, respectively (Mashaghi et al. 2008). Due to the uncertainties of the $\mathrm{dn} / \mathrm{dc}$ for the peptide/lipid complex, the mass values are approximate values for comparison of adsorbed peptide mass between the different membranes.

\section{Preparation of Si wafers for Neutron Reflectometry}

Solid n-type silicon wafers of dimensions $80 \times 40 \times 15 \mathrm{~mm}^{3}$ (Crystran Ltd, Poole, Dorset, UK) were cleaned for 1 hour at $85{ }^{\circ} \mathrm{C}$ in Piranha acid wash $\left(\mathrm{H}_{2} \mathrm{O} / \mathrm{H}_{2} \mathrm{SO}_{4} / \mathrm{H}_{2} \mathrm{O}_{2}\right.$ 4:3:1 by volume). After cleaning in the corrosive acid solution, the Si wafers were rinsed in Milli-Q water and 
dried before being UV-Plasma cleaned for 20 minutes. A final rinse with Milli-Q water and propan-2-ol was carried out before drying under a stream of nitrogen. The silicon wafers were assembled in aluminium cells with a Teflon backing plate which had a solvent reservoir and inlet and outlet tubes to allow for solvent/sample exchange. The sample cells were connected to a Julabo (Seelbach, Germany) recirculating water bath set to $30{ }^{\circ} \mathrm{C}$ to maintain a constant temperature throughout the experiments.

Liposome preparation and deposition onto Si substrate for Neutron Reflectometry

Acyl chain perdeuterated DMPC $\left(\mathrm{d}_{54}-\mathrm{DMPC}\right)$ and DMPG $\left(\mathrm{d}_{54}-\mathrm{DMPG}\right)$ were purchased from Avanti Polar Lipids (Alabaster, AL, USA) and used without further purification. Lipid thin films were prepared in $20 \mathrm{~mL}$ glass vials to give $\mathrm{d}_{54}$-DMPC and $\mathrm{d}_{54}$-DMPC/d $\mathrm{d}_{54}$-DMPG (4:1 molar ratio). The dried lipid thin films were warmed to $37{ }^{\circ} \mathrm{C}$ in a recirculating water bath before being hydrated with a buffered solution of $10 \mathrm{mM}$ MOPS, $150 \mathrm{mM} \mathrm{NaCl} \mathrm{pH} 7.4$ (pD 7.0) in $100 \% \mathrm{D}_{2} \mathrm{O}$ with vortex mixing to a concentration of $0.5 \mathrm{mg} / \mathrm{mL}$. The hydrated lipid solutions were incubated at $37{ }^{\circ} \mathrm{C}$ for 45 minutes before small unilamellar vesicles were prepared by sonicating the lipid solution until clear. Immediately prior to liposome deposition on the silicon substrate and supported lipid bilayer formation, the lipid solutions were further diluted to $0.1 \mathrm{mg} / \mathrm{mL}$ with additional $\mathrm{D}_{2} \mathrm{O}$ buffer. Approximately $5 \mathrm{~mL}$ of liposome solution was flushed through the sample cell at $30{ }^{\circ} \mathrm{C}$ and allowed to incubate for $1 \mathrm{hr}$ before excess was removed using a gentle buffer wash and NR experiments conducted to characterise the bilayer.

Peptide addition to the supported lipid bilayer.

Maculatin 1.1 was dissolved in $100 \% \mathrm{D}_{2} \mathrm{O}$ buffer (10 mM MOPS, $150 \mathrm{mM} \mathrm{NaCl} \mathrm{pH} \mathrm{7.4)} \mathrm{to} \mathrm{a}$ concentration of $10 \mu \mathrm{M}$ immediately before use. Approximately $5 \mathrm{~mL}$ of peptide solution was gently flowed through the sample cell containing the supported lipid bilayer and allowed to 
incubate for 1 hour. Excess, unbound peptide was flushed from the cell with a gentle buffer wash and further NR experiments conducted.

\section{Neutron Reflectometry}

Neutron reflectivity data were measured using the Platypus time-of-flight neutron reflectometer and a cold neutron spectrum $(2.8 \AA \leq \lambda \leq 18.0 \AA)$ at the OPAL 20 MW research reactor (Sydney, Australia) (James et al. 2006; James et al. 2011). Neutron pulses of $20 \mathrm{~Hz}$ were generated using a disc chopper system (EADS Astrium GmbH, Germany) in the low resolution mode $(\Delta \lambda / \lambda=8 \%)$, and recorded on a 2-dimensional helium-3 neutron detector (Denex GmbH, Germany). Reflected beam spectra were collected for each of the surfaces at $0.8^{\circ}$ for 1 hour $(0.6 \mathrm{~mm}$ slits $)$ and $3.0^{\circ}$ for 3 hours $(2.25 \mathrm{~mm}$ slits $)$, respectively, for a $\mathrm{D}_{2} \mathrm{O}$ subphase and $0.6^{\circ}(0.45 \mathrm{~mm}$ slits $)$ for 1 hour and $2.5^{\circ}$ (1.875 $\mathrm{mm}$ slits) for 3 hours for other subphase contrasts. Direct beam measurements were collected under the same collimation conditions for 1 hour each. The data were reduced using the SLIM reduction package (Nelson 2010) which stitches the two data sets together at the appropriate overlap region, re-bins the data at instrument resolution and corrects for background and detector efficiency.

Structural parameters for the native oxide layer on the silicon blocks, lipid bilayer and peptide layers were refined using the MOTOFIT reflectivity analysis software (Nelson 2006) with reflectivity data as a function of the momentum transfer vector, Q, defined as

$$
\mathrm{Q}=4 \pi \sin \theta / \lambda
$$

where $\theta$ is the angle of incidence and $\lambda$ is the neutron wavelength. In the fitting routines, the genetic algorithm was selected to minimize $\chi^{2}$ values by varying the thickness $(\tau)$, roughness $(\sigma)$ and neutron scattering length density $(\rho)$ of each layer.

\section{Neutron Reflection}


Specular neutron reflection is an established technique for studying solid-supported lipid bilayers (Krueger 2001; Wacklin 2010). The intensity of the specularly reflected neutrons from a surface is measured as a function of momentum transfer. Model fitting of the resulting reflectivity profiles yields information on the neutron scattering length density profile normal to the surface, from which the structure of a lipid bilayer may be deduced. The neutron scattering length density, $\rho$, can be considered as a neutron refractive index and is a function of the chemical composition of the material according to

$$
\rho=\mathrm{N}_{\mathrm{A}} \Sigma\left(\mathrm{p}_{\mathrm{i}} / \mathrm{A}_{\mathrm{i}}\right) \mathrm{b}_{\mathrm{i}}, \quad[5]
$$

where $\mathrm{N}_{\mathrm{A}}$ is Avogadro's number, $\mathrm{p}_{\mathrm{i}}$ the mass density, $\mathrm{A}_{\mathrm{i}}$ the atomic mass, and $b_{i}$ the nuclear scattering length of component $i$. The advantage of using neutrons over X-rays, particularly for soft matter systems at the solid-liquid interface, is the difference in scattering length between hydrogen $\left(-3.74 \times 10^{-5} \AA\right)$ and its isotope deuterium $\left(+6.67 \times 10^{-5} \AA\right)$. By selective deuteration of molecules (in this case the phospholipid hydrocarbon tails) different segments of the lipid bilayer can be probed by choosing a suitable solvent contrast. Here we use either a pure $\mathrm{D}_{2} \mathrm{O}$ solvent contrast $\left(\rho=6.35 \times 10^{-6} \AA^{-2}\right.$ ) to highlight the protonated peptide, a mixture of $\mathrm{D}_{2} \mathrm{O}$ and $\mathrm{H}_{2} \mathrm{O}$ where the $\mathrm{nSLD}$ is matched to silicon $\left(\rho=2.07 \times 10^{-6} \AA^{-2}, 38 \% \mathrm{D}_{2} \mathrm{O} / 62 \%\right.$ $\mathrm{H}_{2} \mathrm{O}$ ) to highlight the deuterated tails, and a mixture of $\mathrm{D}_{2} \mathrm{O}$ and $\mathrm{H}_{2} \mathrm{O}$ for which $\rho=4.00 \times 10^{-6}$ $\AA^{-2}$ (contrast match 4, CM4, consisting of $66 \% \mathrm{D}_{2} \mathrm{O} / 34 \% \mathrm{H}_{2} \mathrm{O}$ ).

The structure of the lipid bilayer adsorbed onto the silicon surface can be described as three discrete layers (head group - tail region - head group) with the layer modelled according to its thickness along the surface normal, scattering length density and roughness. The scattering length density of each layer ( $\rho_{\text {layer }}$ ) is a sum of the scattering length density from each component in the layer, thus:

$$
\rho_{\text {layer }}=\varphi_{\text {lipid }} \rho_{\text {lipid }}+\varphi_{\text {peptide }} \rho_{\text {peptide }}+\varphi_{\text {solvent }} \rho_{\text {solvent }}
$$


where $\varphi$ is the volume fraction of each component. If the volume fractions are known, the relative distribution of lipid, peptide and water can be deduced. When changing between different subphase contrasts, the physical structure of the system is assumed not to change. This means that the thickness and roughness parameters in the models are constrained to be the same between each subphase whilst only letting the scattering length density vary. This form of simultaneous fitting provides for a unique solution to the model. Maculatin 1.1 has 25 exchangeable protons and DMPC and DMPG head groups have one and three exchangeable protons respectively. When calculating nSLD values between the different solvent contrasts this is taken into account and nSLD values are adjusted accordingly.

\section{Results:}

DPI measurements of maculatin 1.1 binding to lipid membranes.

In order to accurately determine the effects of maculatin 1.1 on the membrane structure of supported phospholipid bilayers, it is essential that a consistent, homogenous, defect-free and quantitatively defined membrane structure is formed prior to peptide binding. Supported lipid bilayers used were prepared via the in situ liposome deposition technique, which avoids the risk of solvent incorporation that may alter membrane properties and leads to a membrane with a density and structure determined solely by intermolecular forces between lipids. A detailed analysis of SLB formation has previously been conducted using DPI (Mashaghi et al. 2008) in which the intermediate steps in formation of SLB were characterised and followed, including evolution of birefringence and structural properties. Each peptide-membrane binding experiment is divided into several stages: (1) sensor chip and bulk solution calibration, (2) liposome deposition and SLB formation, (3) peptide binding events to the SLB, and (4), chip cleaning/regeneration which removes all bound material. SLBs were prepared by depositing $50 \mathrm{~nm}$ small unilamellar vesicles at $0.1 \mathrm{mg} / \mathrm{mL}$ at $28{ }^{\circ} \mathrm{C}$ in the 
presence of $1 \mathrm{mM} \mathrm{Ca}^{2+}$. Table 1 lists structural parameters obtained for DMPC and DMPC/DMPG (4:1 molar ratio) membranes at $30{ }^{\circ} \mathrm{C}$. Surface area per lipid was calculated based on the adsorbed mass and assumes a unilamellar bilayer with complete surface coverage and for these experiments were found to be $49.8 \AA^{2}$ and $50.1 \AA^{2}$ for DMPC and DMPC/DMPG, respectively. The birefringence of the supported bilayers provides an indication of molecular order and packing within the bilayer and were found to agree with previously established values (Lee et al. 2010a; Lee et al. 2010b).

\section{Interaction of maculatin 1.1 with DMPC supported lipid bilayer.}

The binding of maculatin 1.1 to the DMPC SLB at $30{ }^{\circ} \mathrm{C}$ was examined using the following method in which consecutive injections of $1,2,5,10$ and $20 \mu \mathrm{M}$ maculatin 1.1 were made onto the same bilayer, with each injection performed over a 4 min. period and allowed to equilibrate with running buffer over the chip for a total of 30 minutes before the injection of the next peptide concentration. This technique allows real time changes in bilayer properties to be studied during the formation of lipid-peptide complexes. During each experiment, the real time phase changes in $T_{M}$ and $T_{E}$ waveguide modes were measured and converted into changes in mass and birefringence by using a fixed lipid refractive index of 1.47 . The results for the real time changes in $\mathrm{T}_{\mathrm{M}}$ and $\mathrm{T}_{\mathrm{E}}$ and mass and birefringence are shown in Fig. 1 and 2, respectively. At the lowest concentration of maculatin 1.1, the DMPC bilayer displayed only a small increase in $T_{M}, T_{E}$ response and corresponded to a minor increase in mass with a corresponding minimal increase in birefringence that decreased below its original value during the dissociation phase. Further addition of $2 \mu \mathrm{M}$ maculatin resulted in a minimal increase in $T_{M}$ and $T_{E}$ response, and hence mass, with a minor effect on bilayer birefringence. Increasing the concentration to $5 \mu \mathrm{M}$ resulted in a phase change in $\mathrm{T}_{\mathrm{M}}$ and $\mathrm{T}_{\mathrm{E}}$ nearly 7 times that observed at the previous concentration, while birefringence decreased indicating that lipids within the bilayer began to disorder. The disorder was not permanent and lipids began 
to repack and re-order during the peptide dissociation but not to their original value. A significant amount of peptide was not tightly bound to the surface as there was a considerable drop in mass during peptide dissociation with $\sim 50 \%$ of total peptide mass remaining after dissociation. Further injections of 10 and $20 \mu \mathrm{M}$ maculatin displayed similar significant initial peptide binding with corresponding birefringence decrease, indicating increase in disorder of lipids within the bilayer. As observed at $5 \mu \mathrm{M}$, birefringence, and hence lipid order and packing, began to recover during the dissociation phase, although not to the initial value indicating a more permanent restructuring of the bilayer order to accommodate the bound peptide. The peptide mass bound during these stages likewise increased significantly; however, during the dissociation there was a trend for mass to level off at a certain value, suggesting that a saturation limit of peptide accommodation was reached.

Interaction of maculatin 1.1 with DMPC/DMPG (4:1) supported lipid bilayer.

The effect of maculatin 1.1 on a negatively charged membrane was studied using SLB composed of DMPC/DMPG (4:1) with the same method as employed with the pure DMPC membrane. For the three lowest concentrations of maculatin, 1, 2 and $5 \mu \mathrm{M}$, the mixed lipid bilayer displayed only a minimal increase in $T_{M}$ and $T_{E}$ response (Fig. 1), with a slight increase in the birefringence of the bilayer, indicating increased order within the bilayer. Further addition of $10 \mu \mathrm{M}$ peptide resulted in a sudden rise in the $\mathrm{T}_{\mathrm{M}}$ and $\mathrm{T}_{\mathrm{E}}$ response and a large increase in mass of bound peptide. Bilayer birefringence displayed an initial significant decrease corresponding to the peptide association phase; however, during dissociation, bilayer birefringence was completely restored and indeed increased above its initial level, providing an indication that peptide association allowed the bilayer to re-order to a greater level. During the peptide dissociation phase, bound peptide mass decreased steadily and did not reach equilibrium before the further injection of $20 \mu \mathrm{M}$ maculatin. This concentration of peptide promoted a similar result to the previous concentration with a greater mass of bound 
peptide and corresponding decrease in bilayer birefringence. As seen with the previous concentration, the majority of the bound peptide was lost during the dissociation phase and bilayer birefringence recovered to above its starting value suggesting that saturation of the bilayer (or a critical concentration) may have been achieved.

Bilayer perturbation as a function of bound peptide mass.

As well as measuring the real time changes in bilayer properties caused by the peptide, the effects on the molecular order within the bilayer was examined using changes in bilayer birefringence as a function of the peptide mass bound to the bilayer. This allows us to quantify the extent of peptide induced membrane changes as an addition to the previously described monitoring of the real time behaviour of peptide-membrane interactions.

The changes in birefringence of the DMPC and DMPC/DMPG bilayers according to bound peptide mass are shown in Fig. $2 \mathrm{a}$ and $2 \mathrm{~b}$. At 1 and $2 \mu \mathrm{M}$ for the DMPC bilayer, a small increase in mass was observed with minor decreases in birefringence that is consistent with essentially insignificant change in bilayer ordering. As the peptide concentration was increased to $5 \mu \mathrm{M}$, a significant amount of peptide bound during the association step (2.8 $\mathrm{ng} / \mathrm{mm}^{2}$ ) (Fig. 2e) with a decrease in birefringence (Fig. 2c), which reached a minimum of 0.0182 at the end of the association step and then increased slightly during the dissociation but then dropped to $\sim 0.0186$ at the end of the peptide dissociation. Approximately 1.5 $\mathrm{ng} / \mathrm{mm}^{2}$ of peptide remained bound to the bilayer and is consistent with the peptide initially binding and causing a decrease in bilayer ordering. During dissociation, peptide was lost and bilayer order partially recovered before equilibrating. Further injections of 10 and $20 \mu \mathrm{M}$ peptide resulted in similar association curves, with bound peptide increasing to a maximum of 5.14 and $5.5 \mathrm{ng} / \mathrm{mm}^{2}$, respectively, during association with a significant decrease in birefringence, which partially recovered during dissociation before dropping again to a lower 
level. In each case the bilayer birefringence continually decreased after each binding step, indicating that continuing injections of peptide had a cumulative disruptive effect on bilayer order.

Prior to peptide injections, birefringence of the mixed (anionic) lipid bilayer was slightly greater than that of the pure DMPC bilayer (Fig. $2 b$ and $2 d$ ) indicating that the mixed lipid system formed a more ordered bilayer. Addition of 1,2 and $5 \mu \mathrm{M}$ maculatin to the bilayer resulted in a minimal increase in bound mass $\left(<0.06 \mathrm{ng} / \mathrm{mm}^{2}\right)$ that slightly increased bilayer birefringence, indicating that addition of small amounts of peptide increased order by possibly increasing the packing within the bilayer. A slight mass decrease occurred during the dissociation phase, suggesting that the peptide remained mostly irreversibly bound to the bilayer and had not yet reached saturation. Addition of $10 \mu \mathrm{M}$ maculatin appeared to pass some threshold value as a significant amount of peptide bound to the bilayer $\left(1.9 \mathrm{ng} / \mathrm{mm}^{2}\right)$ and initially during the association phase caused a rapid decrease in bilayer birefringence (0.0202 to 0.0188 ). However, on removal of peptide from the buffer during the dissociation phase, bilayer birefringence increased significantly to above its initial value while a significant amount of peptide remained bound $\left(1.28 \mathrm{ng} / \mathrm{mm}^{2}\right)$, consistent with an enhanced degree of bilayer order driven by probable peptide incorporation (Fig. $2 \mathrm{~b}, 2 \mathrm{~d}$ and $2 \mathrm{f}$ ). A further addition of $20 \mu \mathrm{M}$ maculatin to the bilayer resulted in an additional $1.2 \mathrm{ng} / \mathrm{mm}^{2}$ of peptide binding during association with a further drop in birefringence below that of the 10 $\mu \mathrm{M}$ peptide. During dissociation, the peptide mass decreased significantly to close to its previous value $\left(1.32 \mathrm{ng} / \mathrm{mm}^{2}\right)$ with birefringence increasing to just below the preceding value. These results indicate that a threshold or maximum amount of bound peptide was achieved with only transient reversible bilayer changes occurring above concentrations of 10 $\mu \mathrm{M}$ peptide. 
Characterisation of Maculatin 1.1 binding to phospholipid bilayers by Neutron Reflectometry

The bilayers were deposited onto silica surfaces by in situ vesicle deposition (Kalb et al. 1992). The silica layer was found to be $15 \AA$ thick with an interfacial roughness of $4 \AA$, which was used for all subsequent fits to the bilayers. Acyl-chain deuterated lipids were used so as to provide contrast against the protonated peptide. The supported bilayers were measured under two subphase contrasts of $\mathrm{D}_{2} \mathrm{O}$ and CM4 (Fig. 3). The NR profiles of the deposited bilayers displayed clear differences between just $\mathrm{D}_{2} \mathrm{O}$ in contact with silica and the deposited bilayer in $\mathrm{D}_{2} \mathrm{O}$ suggesting bilayer formation (Fig. 3). The bilayer data were fitted using a three layer model with head group 1 being the head groups closest to the silica surface, the centre region consisting of the (deuterated) hydrocarbon tails and, finally, head group 2 being those in contact with the bulk solvent. In some previous neutron reflectivity studies, supported lipid bilayers have been fitted with an additional $\sim 3$ to $5 \AA$ A solvent cushion between the silica surface and the adjacent head groups (Callow et al. 2005; Johnson et al. 1991; Kiessling and Tamm 2003). We attempted to fit our observed neutron reflectivity data with this adjacent water layer in the model; however, given the Q range of our data we were unable to resolve the solvent cushion as a discrete layer and saw no improvement in the quality of the fit.

The three layer model used to define the bilayer was modelled according to its thickness, nSLD and roughness (fixed at $4 \AA$ for each layer). The dimensions of the bilayers can be seen in Tables 2 and 3 with the overall thickness (sum of head group and tail layers) of each bilayer being $46 \pm 4 \AA$ and $43 \pm 3 \AA$ for the DMPC only and mixed DMPC/DMPG bilayers, respectively; the same (within error) as that measured using DPI. The area per lipid molecule is $78 \pm 8 \AA^{2}$ for the DMPC bilayer and $75 \pm 6 \AA^{2}$ for the mixed DMPC/DMPG bilayer. The experiments were carried out at $30^{\circ} \mathrm{C}$, which is above the phase transition temperature of both 
DMPC and DMPG $\left(\mathrm{T}_{\mathrm{m}} \sim 23^{\circ} \mathrm{C}\right)$. Although our calculated values are, on face value, higher than those reported from X-ray diffraction data from multi-lamellar DMPC bilayers in the L $\alpha$ phase (Costigan et al. 2000; Nagle and Tristram-Nagle 2000; Petrache et al. 1998; Cornell and Separovic 1983), the calculated area per lipid molecule is consistent if the surface coverage of the bilayer is taken into account. The hydrophobic tail region of the bilayers was partially hydrated as there was a difference in scattering length density of the deuterated lipid acyl chain region between the $\mathrm{D}_{2} \mathrm{O}$ and CM4 contrasts (Fig. 4), which is suggestive of solvent penetration. From this the volume fractions of the bilayers were calculated to be $0.69 \pm 0.05$ for the DMPC bilayer and $0.83 \pm 0.07$ for the DMPC/DMPG mixed bilayer. Although surface coverage was incomplete, these volume fractions are well within what has previously been shown to be sufficient coverage for studying bilayer membrane structures (Koenig et al. 1996; Wacklin and Thomas 2007). To check if maculatin 1.1 was binding to the bare surface, quartz crystal microbalance-dissipation (QCM-D) was used to test the peptide interaction with $\mathrm{SiO}_{2}$ sensor chips of similar surface composition to the silica wafer and no interaction was observed. The lipid head groups in contact with the silica surface were more solvated than those exposed to the bulk solvent (Tables 2 and 3, and Fig. 4a), which can be accounted for by the unresolved solvent cushion between the head groups and the silica surface artificially increasing the apparent solvent content.

\section{Interaction of maculatin 1.1 in supported DMPC bilayer}

Using NR the effect of maculatin 1.1 binding on supported phospholipid bilayers has been observed. Maculatin 1.1 was added to the bilayer at a concentration of $10 \mu \mathrm{M}$ at $\mathrm{pH} 7.0$, which has previously been shown by QCM-D studies to disrupt DMPC bilayers (Mechler et al. 2007) although, given the lack of significant bilayer disruption observed by DPI with more complete bilayers, may depend on an incomplete surface coverage facilitating peptide interaction. Upon addition of maculatin 1.1 to the bilayer, reflectivity decreased more sharply 
at lower Q (Fig. 3a) indicating that the peptide bound to the bilayer. Following binding, the overall total thickness of the bilayer remained unchanged at $46 \pm 3 \AA$ while the scattering length density profile of the DMPC bilayer with bound maculatin 1.1 showed a decrease in the deuterated tail region (Fig. 4a), consistent with a hydrogenous peptide inserting into the deuterated hydrocarbon core of the bilayer. The volume fraction of the lipid bilayer tails remained unchanged (within error) at $0.70 \pm 0.04$ with the peptide volume fraction being 0.24 . The thickness of the tail region of the bilayer in the presence of maculatin 1.1 increased slightly from $29 \pm 2$ to $30 \pm 1 \AA$, which is within error (Table 2 ) suggesting that maculatin 1.1 had minimal effect on tail order in DMPC only bilayers. Maculatin, however, had interesting effects on the lipid head groups. The thickness of head group two increased from $9 \pm 1$ to 10 $\pm 1 \AA$, suggesting a negligible effect from maculatin 1.1 . Upon maculatin 1.1 binding the scattering length density of both head group layers increased, which is indicative of an increase in the solvent content of the bilayer head groups (Table 2).

Interaction of maculatin 1.1 in DMPC/DMPG (4:1) supported lipid bilayer

When maculatin 1.1 at $10 \mu \mathrm{M}$ and $\mathrm{pH} 7.0$ bound to the mixed bilayer of DMPC/DMPG the reflectivity profile changed significantly (Fig. $3 b$ and $3 c$ ) and there was a decrease in the scattering length density of the tail region as seen for the DMPC only bilayer (Fig. 4b). The volume fraction of the bilayer tails reduced from 0.83 to $0.59 \pm 0.02$ suggesting removal of lipid material from the surface. The volume fraction of the peptide was 0.25 with the remaining 0.16 being solvent. The overall thickness of the bilayer increased slightly from 43 to $45 \pm 3 \AA$ with most of the increase in thickness seen in the tail region which increased from $25 \pm 1 \AA$ to $28 \pm 1 \AA$ (Table 3 ) demonstrating that in the negatively charged bilayer the tail order increased, which was also observed by DPI. Unlike the DMPC only bilayer, a marked effect was seen in head group 2 of the mixed DMPC/DMPG bilayer. The thickness of head group 2 decreased from $9 \pm 1 \AA$ to $6 \pm 1 \AA$ (Table 3 ) due to a strong interaction between 
the anionic head groups and the cationic peptide. The decrease in head group thickness could be interpreted as the head groups becoming more parallel with the plane of the phospholipid bilayer. Little effect apart from some increased solvation was seen for head group 1 (which is close to the silicon oxide surface) upon maculatin 1.1 binding.

When modelling the presence of maculatin in both the DMPC and DMPC/DMPG bilayer, the optimal approach was to use a three layer model of head groups-tails-head groups. When the tail region was split into two discrete layers (lower and upper tails), the nSLD of each layer converged to the same value. Therefore, the tails were modelled as a single layer since reducing the number of parameters resulted in a more reliable fit. Including an additional peptide layer above the outer head groups resulted in a poor fit, which discounted peripheral maculatin binding. The wash step prior to taking the neutron reflectivity, most likely would have removed any peripherally bound peptide. 


\section{Discussion}

With the exact mode of action of antimicrobial peptides uncertain due to a lack of understanding of membrane structure prior to, during and following peptide interaction, it is important to obtain high resolution information on the spatial changes in bilayer properties as well as structural perturbations. Peptide interactions with different components within a membrane will alter the structure and the dynamic properties of the membrane. Small localised disruptions to lipid molecules may result in global structure and property alterations such as a shift in lipid packing, membrane thickness, density and bilayer order, which consequently will impact the function of the membrane and hence cell activity. The aim of this investigation is to study the temporal changes in bilayer properties during peptide binding events as well as obtain detailed information on the spatial changes in bilayer components and location of the peptide following interaction with SLB.

Although a wide range of membrane models are available to study peptide-membrane interactions, we have chosen relatively simple DMPC and DMPG models for our study. Both DMPC and DMPG have fully saturated acyl chains, which removes any effects on bilayer order arising from unsaturated double bonds and aids the effects of the peptide to be examined. In addition, both lipids have been studied extensively and characterised for their physical and structural properties allowing validation of high resolution structural data. Phosphatidylcholine lipids are abundant within eukaryotic membranes (de Kroot 2007; Gunstone and Harwood 2007) and have been an acceptable model for the surface of mammalian cells. The lipid composition of bacteria varies among species and growing conditions but bacterial cell membranes generally contain more lipids with anionic headgroups (Epand and Epand 2009), providing an overall net negative charge, which is effectively mimicked by use of phosphatidylglycerol in the membrane composition. 
In this study we have analysed the membrane binding of maculatin 1.1 using DPI and NR to provide information on changes in membrane structure and properties upon peptide binding. While the bilayers produced by each technique differ in terms of surface coverage, the measured values for the bilayer properties are sufficiently similar to enable an effective comparison to be made. Individually, DPI allows real-time analysis of membrane structure changes during peptide binding through measurements of bilayer order (birefringence) and mass changes. In combination with NR, which can directly measure the extent of any peptide induced changes within the bilayer structure and gives an indirect measure of changes in order of bilayer components, these two techniques provide an effective complement for the study of AMP-membrane interactions.

\section{Interaction of maculatin 1.1 with supported lipid bilayers}

Using DPI and NR, the physical properties of maculatin 1.1 interaction with DMPC and mixed DMPC/DMPG bilayers have been characterised according to the amount of mass binding, the extent of molecular reordering as a function of mass, the impact on structural parameters throughout the binding process, as well as alterations in the cross sectional distribution of bilayer components following peptide binding. The ability to characterise each bilayer system using a range of structural parameters such as thickness, density, mass and molecular order (birefringence) allows an accurate quantitative tracking of bilayer in real time; while being able to track and quantify changes in the distribution of bilayer components prior to and following peptide interaction provides powerful information on the mode of interaction adopted by the peptide.

The effect of maculatin 1.1 on acyl chain order in phospholipid bilayers

Differences were observed between the lipid headgroup and acyl chains of the DMPC and DMPC/DMPG bilayers with the acyl chains of the mixed bilayer being shorter and less 
ordered (Tables 2 and 3, and Fig. 4) but, given that this was only observed through NR, may be related to the lower surface coverage creating a less constrained and ordered surface. Maculatin 1.1 was shown to bind significantly to both DMPC and mixed DMPC/DMPG bilayers; however, the amount and mode of peptide binding differed between the two bilayer types. In the neutral DMPC bilayer, each peptide binding event involved a significant amount of peptide absorbing to the surface with transient increases in birefringence during peptide association events, which correspond to the peptide inserting and constraining lipid motion such that bilayer order increased. As peptide was removed from solution much of the bound peptide left the surface and triggered a molecular reordering which resulted in a considerably more disordered state after each consecutive peptide injection. Although difficult to state the mode of peptide insertion conclusively from DPI and NR alone, it appears that peptide interaction causes more general bilayer disruption, which is generally consistent with the findings of previous studies such as solid-state NMR (Fernandez et al. 2011).

The binding profile of maculatin in the anionic mixed lipid bilayer differed significantly from that observed for the neutral SLB. In terms of mass bound and bilayer disturbance, a lower amount of peptide was required to induce a given level of bilayer order perturbation compared to the DMPC bilayer. In other words, on a mass for mass basis, the peptide was more effective at interacting with the anionic bilayer, which is consistent with other studies (Ambroggio et al. 2005; Balla et al. 2004; Fernandez et al. 2011; Gehman et al. 2008; Mechler et al. 2007; Seto et al. 2007) and likely relates to the importance of overall bilayer charge in mediating antimicrobial peptide activity. Little effect on bilayer ordering was observed at lower concentrations but a significant amount of peptide bound at $10 \mu \mathrm{M}$ and caused an initial disordering effect that was followed by a molecular reordering as excess peptide washed away. This bilayer ordering effect was also observed through NR and is likely due to peptide binding and inserting into the bilayer in such a manner as to decrease 
lipid motional flexibility. Evidence of probable transmembrane pore formation is detailed by the significant additional solvent penetration throughout the entire bilayer with retention of overall global bilayer structure. This is consistent with phosphorus and deuterium solid-state NMR studies (Fernandez et al. 2011) of DMPC/DMPG lipid bilayers, which revealed lipid domain segregation without loss of overall bilayer structure.

\section{The effect of maculatin 1.1 on head group orientation}

Maculatin 1.1 is a 21 amino acid long peptide which, when in an $\alpha$-helical conformation could span a lipid bilayer (Killian et al. 1998). When maculatin 1.1 bound to phospholipid bilayers an increase in the solvent content of both head group 1 and head group 2 was observed, indicating that the peptide perforates the bilayer for both model membrane systems. Maculatin had a profound effect on the lipid head groups that faced the bulk solvent

in the mixed DMPC/DMPG bilayer (Table 3). Solid-state ${ }^{31} \mathrm{P}$ NMR showed that maculatin 1.1 interacts with the phospholipid head groups of anionic bilayers in such a way as to promote lipid segregation and domain formation (Gehman et al. 2008; Fernandez et al. 2011), and disorders the phosphatidylcholine (PC) head groups (Balla et al. 2004; Gehman et al. 2008; Marcotte et al. 2003). In this study a small increase was seen in the thickness of the PC head groups close to the bulk solvent (Fig. 4a) together with an increase in scattering length density, suggesting an increase in hydration of the head group region.

The mode of action of maculatin 1.1 on neutral and anionic phospholipid bilayers

A number of different proposed mechanisms exist to describe how antimicrobial peptides may act on a membrane (Oren and Shai 1999; Shai 1999, 2002; Shai and Oren 2001; Yang et al. 2001). Their mode of action depends on the structure of the peptide and membrane composition. In this study we have shown that maculatin 1.1 exhibits a different interaction depending on the composition of the membrane. The peptide inserts into phospholipid 
bilayers and spans the lipid acyl chain region. Previous QCM-D analysis of maculatin with both DMPC and DMPC/DMPG bilayers indicate that the peptide spans the bilayer upon insertion. However, in the anionic bilayer a pore appeared to form and for neutral membranes, disordered mixed lipid-peptide structures formed which were associated with loss of material from the bilayer structure (Mechler et al. 2007). In this work a bilayer structure was retained with maculatin 1.1 (Fig. 4) but the lipid volume fraction was reduced, indicating a loss of material from the bilayer surface. The QCM-D data also showed that 10 $\mu \mathrm{M}$ peptide (as used in this study) is not sufficient to remove lipid material from a DMPC/DMPG bilayer. However, the incomplete initial surface coverage may have enhanced peptide interaction as no loss of bilayer material was observed even at $20 \mu \mathrm{M}$ for the DPI experiments. We observed a reduction in the lipid volume fraction in the DMPC/DMPG bilayer in the presence of maculatin 1.1 . This reduction in lipid volume is likely to be due to a combination of a change in the lipid packing associated with the increase in order of the lipid acyl chains as well as a partial loss of material, again related to the initial incomplete surface coverage facilitating peptide interaction. From these results and previous work we propose that maculatin 1.1 binds to neutral bilayers in a manner which progressively perturbs lipid structure; while in the mixed DMPC/DMPG bilayer, little effect is seen until a certain peptide concentration is exceeded at which point a reordering of lipid structure occurs associated with pore formation.

\section{Conclusion}

Dual polarisation interferometry and neutron reflectometry data of maculatin 1.1 in supported model membrane systems indicated a mode of action dependent on bilayer charge. Maculatin 1.1 inserted into both neutral and anionic lipid bilayers and induced a progressive 
concentration dependent disordering of neutral bilayers. In contrast, maculatin had a stronger interaction with anionic bilayers and interacted in a manner promoting bilayer reordering consistent with transmembrane pore formation. DPI is able to probe the global changes in bilayer order induced by the peptide while NR gives insights into changes within the bilayer structure. These two complementary techniques are useful for the analysis of peptidemembrane interactions and, in the case of maculatin 1.1, highlight the importance of membrane charge in mediating AMP-membrane interactions. 


\section{Acknowledgments}

MIA and FS thank the Australian Research Council (ARC) for financial support. FS would

like to acknowledge the Australian Institute for Nuclear Science and Engineering (AINSE)

(proposal ID: P1139) for their support and funding enabling this research. DIF thanks the

Australian government for an Australian Postgraduate Award. We would like to thank Assoc.

Prof. Lisa Martin and Ms Stefania Piantavigna (Monash University) for their assistance with

QCM-D. APLB acknowledges the Australian Nuclear Science and Technology Organisation

(ANSTO) executive for funding.

\section{References}

Ambroggio EE, Separovic F, Bowie JH, Fidelio GD, Bagatolli LA (2005) Direct visualisation of membrane leakage induced by the antibiotic peptides: Maculatin, citropin, and aurein. Biophysical Journal 89 (3):1874-1881

Balla MS, Bowie JH, Separovic F (2004) Solid-state NMR study of antimicrobial peptides from Australian frogs in phospholipid membranes. European Biophysics Journal with Biophysics Letters 33 (2):109-116. doi:10.1007/s00249-003-0342-7

Binder H, Zschornig O (2002) The effect of metal cations on the phase behavior and hydration characteristics of phospholipid membranes. Chemistry and Physics of Lipids 115:39-61

Boland M, Separovic F (2006) Membrane interactions of antimicrobial peptides from Australian tree frogs. Biochimica et Biophysica Acta 1758:1178-1183

Brinkworth CS, Bowie JH (2003) Negative ion electrospray mass spectra of the maculatin peptides from the tree frogs Litoria genimaculata and Litoria eucnemis. Rapid Communications in Mass Spectrometry 17:2215-2225

Callow P, Fragneto G, Cubitt R, Barlow DJ, Lawrence MJ, Timmins P (2005) Interaction of Cationic Lipid Vesicles with Model Cell Membranes As Determined by Neutron Reflectivity. Langmuir 21 (17):7912-7920. doi:doi: 10.1021/la0509571

Casillas-Ituarte NN, Chen X, Castada H, Allen $\mathrm{HC}(2010) \mathrm{Na}^{+}$and $\mathrm{Ca}^{2+}$ Effect on the Hydration and Orientation of the Phosphate Group of DPPC at Air=Water and AirHydrated Silica Interfaces. Journal of Physical Chemistry 114:9485-9495

Chia BCS, Carver J, Mulhern TD, Bowie JH (2000) Maculatin 1.1, an anti-microbial peptide from the Australian tree frog, Litoria genimaculata. Solution structure and biological activity. European Journal of Biochemistry 267:1894-1908

Chia CSB, Torres J, Cooper MA, Arkin IT, Bowie JH (2002) The orientation of the antibiotic peptide maculatin 1.1 in DMPG and DMPC lipid bilayers. Support for a pore-forming mechanism. FEBS Letters 512:47-51 
Cornell BA, Separovic F (1983) Membrane thickness and acyl chain length. Biochimica et Biophysica Acta - Biomembranes 733 (1):189-193

Costigan SC, Booth PJ, Templer RH (2000) Estimations of lipid bilayer geometry in fluid lamellar phases. Biochimica et Biophysica Acta-Biomembranes 1468 (1-2):41-54

De Feijter JA, Benjamins J, Veer FA (1978) Ellipsometry as a tool to study the adsorption behavior of synthetic and biopolymers at the air-water interface. Biopolymers 17 (7):1759-1772

de Kroot AIPM (2007) Metabolism of phosphatidylcholine and its implications for lipid acyl chain composition in Saccharomyces cerevisiae. Biochimica et Biophysica Acta, Molecular and Cell Biology of Lipids 1771 (3):343-352

Epand RM, Epand RF (2009) Domains in bacterial membranes and the action of antimicrobial agents. Molecular Biosystems 5 (6):580-587

Fernandez DI, Gehman JD, Separovic F (2009) Membrane interactions of antimicrobial peptides from Australian frogs. Biochimica et Biophysica Acta 1788:1630-1638

Fernandez DI, Sani M-A, Separovic F (2011) Interactions of the Antimicrobial Peptide Maculatin 1.1 and Analogues with Phospholipid Bilayers. Australian Journal of Chemistry 64:798-805

Gehman JD, Luc F, Hall K, Lee T-H, Boland MP, Pukala TL, Bowie JH, Aguilar MI, Separovic F (2008) Effect of antimicrobial peptides from Australian tree frogs on anionic phospholipid membranes. Biochemistry 47 (33):8557-8565. doi:10.1021/bi800320v

Gunstone FD, Harwood JL (2007) Occurrence and characterisation of oils and fats. In: Gunstone FD, Harwood JL, Dijkstra AJ (eds) The Lipids Handbook. CRC Press, Taylor and Francis Group, pp 37-141

James M, Nelson A, Brule A, Schulz JC (2006) Platypus: a time-of-flight neutron reflectometer at Australia's new research reactor. Journal of Neutron Research 14 (2):91-108

James M, Nelson A, Holt SA, Saerbeck T, Hamilton WA, Klose F (2011) The multipurpose time-of-flight neutron reflectometer "Platypus" as Australia's OPAL reactor. Nuclear Instruments and Methods in Physics Research Section A: Accelerators, Spectrometers, Detectors and Associated Equipment 632 (1):112-123. doi:DOI: 10.1016/j.nima.2010.12.075

Johnson SJ, Bayerl TM, McDermott DC, Adam GW, Rennie AR, Thomas RK, Sackmann E (1991) Structure of an adsorbed dimyristoylphosphatidylcholine bilayer measured with specular reflection of neutrons. Biophysical Journal 59 (2):289-294. doi:DOI: 10.1016/S0006-3495(91)82222-6

Kalb E, Frey S, Tamm LK (1992) Formation of supported planar bilayers by fusion of vesicles to supported phospholipid monolayers. Biochimica et Biophysica Acta (BBA) - Biomembranes 1103 (2):307-316. doi:DOI: 10.1016/0005-2736(92)90101-Q

Kiessling V, Tamm LK (2003) Measuring Distances in Supported Bilayers by Fluorescence Interference-Contrast Microscopy: Polymer Supports and SNARE Proteins. Biophysical Journal 84 (1):408-418. doi:DOI: 10.1016/S0006-3495(03)74861-9

Killian JA, de Planque MRR, van der Wel PCA, Salemink I, de Kruijff B, Greathouse DV, Koeppe II RE (1998) Modulation of membrane structure and function by hydrophobic mismatch between proteins and lipids. Pure \& Applied Chemistry 70 (1):75-82

Koenig BW, Krueger S, Orts WJ, Majkrzak CF, Berk NF, Silverton JV, Gawrisch K (1996) Neutron Reflectivity and Atomic Force Microscopy Studies of a Lipid Bilayer in Water Adsorbed to the Surface of a Silicon Single Crystal. Langmuir 12 (5):13431350. doi:doi: 10.1021/la950580r 
Koenig BW, Strey HH, Gawrisch K (1997) Membrane Lateral Compressibility Determined by NMR and X-Ray Diffraction: Effect of Acyl Chain Polyunsaturation. Biophysical Journal 73:1954-1966

Krueger S (2001) Neutron reflection from interfaces with biological and biomimetic materials. Current Opinion in Colloid \& Interface Science 6 (2):111-117

Lee T-H, Hall KN, Swann MJ, Popplewell JF, Unabia S, Park Y, Hahm K-S, Aguilar M-I (2010a) The membrane insertion of helical antimicrobial peptides from the Nterminus of Helicobacter pylori ribosomal protein L1. Biochimica et Biophysica Acta 1798:544-557

Lee T-H, Heng C, Swann MJ, Gehman JD, Separovic F, Aguilar M-I (2010b) Real-time quantitative analysis of lipid disordering by aurein 1.2 during membrane adsorption, destabilisation and lysis. Biochimica et Biophysica Acta 1798:1977-1986

Marcotte I, Wegener KL, Lam Y-H, Chia BCS, Planque MRRd, Bowie JH, Auger M, Separovic F (2003) Interaction of antimicrobial peptides from Australian amphibians with lipid membranes. Chemistry and Physics of Lipids 122 (1-2):107-120. doi:10.1016/S0009-3084(02)00182-2

Mashaghi A, Swann M, popplewell J, Textor M, Reimhult E (2008) Optical anisotropy of supported lipid structures probed by waveguide spectroscopy and its application to study of supported lipid bilayer formation kinetics. Analytical Chemistry 80 (10):3666-3676

Mechler A, Praporski S, Atmuri K, Boland M, Separovic F, Martin LL (2007) Specific and selective peptide-membrane interactions revealed using quartz crystal microbalance. Biophysical Journal 93:3907-3916

Nagle JF, Tristram-Nagle S (2000) Structure of lipid bilayers. Biochimica et Biophysica Acta-Reviews on Biomembranes 1469 (3):159-195

Nelson A (2006) Co-refinement of multiple-contrast neutron/X-ray reflectivity data using MOTOFIT. Journal of Applied Crystallography 39:273-276

Nelson A (2010) Motofit - integrating neutron reflectometry acquisition, reduction and analysis into one, easy to use, package. Journal of Physics: Conference Series 251 (1):012094

Niidome T, Kobayashi K, Arakawa H, Hatakeyama T, Aoyagi H (2004) Structure-activity relationship of an antibacterial peptide, maculatin 1.1 from the skin glands of the tree frog, Littoria genimaculata. Journal of Peptide Science 10:414-422

Oren Z, Shai Y (1999) Mode of action of linear amphipathic $\alpha$-helical antimicrobial peptides. Biopolymers (Peptide Science) 47:541-463

Pedersen UR, Leidy C, Westh P, Peters GH (2006) The effect of calcium on the properties of charged phospholipid bilayers. Biochimica et Biophysica Acta 1758:573-582

Petrache HI, Tristram-Nagle S, Nagle JF (1998) Fluid phase structure of EPC and DMPC bilayers. Chemistry and Physics of Lipids 95 (1):83-94

Rozek T, Waugh RJ, Steinborner ST, Bowie JH, Tyler MJ, Wallace JC (1998) The maculatin peptides from the skin glands of the tree frog Littoria genimaculata: a comparison of the structures and antibacterial activities of maculatin 1.1 and caerin 1.1. Journal of Peptide Science 4 (2):111-115

Seto GWJ, Marwaha S, Kobewka DM, Lewis RNAH, Separovic F, McElhaney RN (2007) Interactions of the Australian tree frog antimicrobial peptides aurein 1.2, citropin 1.1 and maculatin 1.1 with lipid model membranes: Diferential scanning calorimetric and Fourier transform infrared spectroscopic studies. Biochimica et Biophysica Acta 1768:2787-2800 
Shai Y (1999) Mechanism of the binding, insertion and destabilisation of phospholipid bilayer membranes by $\alpha$-helical antimicrobial and cell non-selective membrane lytic peptides. Biochimica et Biophysica Acta 1462:55-70

Shai Y (2002) Mode of action of membrane active antimicrobial peptides. Biopolymers 66 (4):236-248

Shai Y, Oren Z (2001) From "carpet" mechanism to de-novo designed diastereomeric cellselective antimicrobial peptides. Peptides 22:1629-1641

Terry CJ, Popplewell JF, Swann MJ, Freeman NJ, Fernig DG (2006) Characterisation of membrane mimetics on a dual polarisation interferometer. Biosensors and Bioelectronics 22:627-632

VanCompernolle SE, Taylor RJ, Richter KO, Jiang J, Youree BE, Bowie JH, Tyler MJ, Conlon JM, Wade D, Aiken C, Dermody TS, KewelRamani VN, Rollins-Smith LA, Unutmaz D (2005) Antimicrobial peptides from amphibian skin potently inhibit human immunodeficiency virus infection and transfer of virus from dendritic cells to T cells. Journal of Virology 79 (18):11598-11606

Wacklin HP (2010) Neutron reflection from supported lipid membranes. Current Opinion in Colloid \& Interface Science 15 (6):445-454

Wacklin HP, Thomas RK (2007) Spontaneous formation of asymmetric lipid bilayers by adsorption of vesicles. Langmuir 23 (14):7644-7651

Yang L, Harroun TA, Weiss TM, Ding L, Huang HW (2001) Barrel-stave model or toroidal model? A case study on melittin pores. Biophysical Journal 81:1475-1485 


\section{Tables and Figures}

Table 1. Typical structural parameters of supported lipid bilayers on FB80 planar silicon oxynitride waveguide chips.

\begin{tabular}{|l|c|c|c|c|c|}
\hline Lipid & $\begin{array}{c}\text { Density } \\
\left(\mathrm{g} / \mathrm{cm}^{3}\right)\end{array}$ & $\begin{array}{c}\text { Thickness* } \\
(\AA)\end{array}$ & $\begin{array}{c}\text { Mass } \\
\left(\mathrm{ng} / \mathrm{mm}^{2}\right)\end{array}$ & Birefringence & $\begin{array}{c}\text { Area }^{\#} \\
\left(\AA^{2} / \mathrm{lipid}\right)\end{array}$ \\
\hline DMPC & $1.0026 \pm 0.003$ & $45.1 \pm 0.6$ & $4.51 \pm 0.06$ & $0.0193 \pm 0.0007$ & $49.8 \pm 0.7$ \\
\hline DMPC/DMPG(4:1) & $1.0068 \pm 0.003$ & $44.9 \pm 1.7$ & $4.52 \pm 0.16$ & $0.0199 \pm 0.0009$ & $50.1 \pm 1.8$ \\
\hline
\end{tabular}

*Thickness is calculated using a fixed isotropic refractive index of the lipid film of 1.47 (Mashaghi et al. 2008; Lee et al. 2010b).

"Assumes formation of unilamellar bilayer with complete surface coverage.

Lipid area calculated from DPI experiments is lower than $\mathrm{X}$ ray diffraction and NMR values (Cornell and Separovic 1983; Nagle and Tristram-Nagle 2000; Koenig et al. 1997) due to the presence of partial multilayers and/or the effect of $\mathrm{Ca}^{2+}$ on increasing lipid packing density (Mashaghi et al. 2008; Binder and Zschornig 2002; Casillas-Ituarte et al. 2010; Pedersen et al. 2006). 
Table 2. Effect of maculatin $1.1^{\mathrm{a}}$ on the properties of the DMPC bilayer.

\begin{tabular}{|c|c|c|c|c|}
\hline & \multicolumn{2}{|c|}{ No Maculatin 1.1 } & \multicolumn{2}{c|}{ With Maculatin 1.1 } \\
\cline { 2 - 5 } & $\begin{array}{c}\text { Thickness } \\
(\AA)\end{array}$ & $\begin{array}{c}\rho_{\text {layer }} \text { in } \mathrm{D}_{2} \mathrm{O} \\
\left(\times 10^{-6} \AA^{-2}\right)\end{array}$ & $\begin{array}{c}\text { Thickness } \\
(\AA)\end{array}$ & $\begin{array}{c}\rho_{\text {layer }} \text { in } \mathrm{D}_{2} \mathrm{O} \\
\left(\times 10^{-6} \AA^{-2}\right)\end{array}$ \\
\hline Head group 1 & $8 \pm 1$ & $3.84 \pm 0.31$ & $6 \pm 1$ & $5.42 \pm 0.37$ \\
\hline Tails & $29 \pm 2$ & $6.67 \pm 0.47$ & $30 \pm 1$ & $5.46 \pm 0.06$ \\
\hline Head group 2 & $9 \pm 1$ & $4.01 \pm 0.28$ & $10 \pm 1$ & $5.77 \pm 0.16$ \\
\hline
\end{tabular}

${ }^{\text {a }}$ Molecular mass $=2128.8 \mathrm{~g} \mathrm{~mol}^{-1}$, volume $=3494.4 \AA^{3}, \rho=2.66 \times 10^{-6} \AA^{-2}$ in $\mathrm{D}_{2} \mathrm{O}$

Supported lipid bilayers fitted using a four box model of silicon oxide (thickness fixed at 15 $\AA$ ) and a three layer lipid bilayer, with interfacial roughness fixed at $4 \AA$ for all layers.

Table 3. Effect of maculatin 1.1 on the properties of the mixed DMPC/DMPG bilayer.

\begin{tabular}{|c|c|c|c|c|}
\hline \multirow{2}{*}{} & \multicolumn{2}{|c|}{ No Maculatin 1.1 } & \multicolumn{2}{c|}{ With Maculatin 1.1 } \\
\cline { 2 - 5 } & $\begin{array}{c}\text { Thickness } \\
(\AA)\end{array}$ & $\begin{array}{c}\rho_{\text {layer }} \text { in } \mathrm{D}_{2} \mathrm{O} \\
\left(\times 10^{-6} \AA^{-2}\right)\end{array}$ & $\begin{array}{c}\text { Thickness } \\
(\AA)\end{array}$ & $\begin{array}{c}\rho_{\text {layer }} \text { in } \mathrm{D}_{2} \mathrm{O} \\
\left(\times 10^{-6} \AA^{-2}\right)\end{array}$ \\
\hline Head group 1 & $9 \pm 1$ & $4.49 \pm 0.40$ & $11 \pm 1$ & $5.28 \pm 0.13$ \\
\hline Tails & $25 \pm 1$ & $6.73 \pm 0.54$ & $28 \pm 1$ & $5.43 \pm 0.06$ \\
\hline Head group 2 & $9 \pm 1$ & $4.29 \pm 0.34$ & $6 \pm 1$ & $4.62 \pm 0.26$ \\
\hline
\end{tabular}




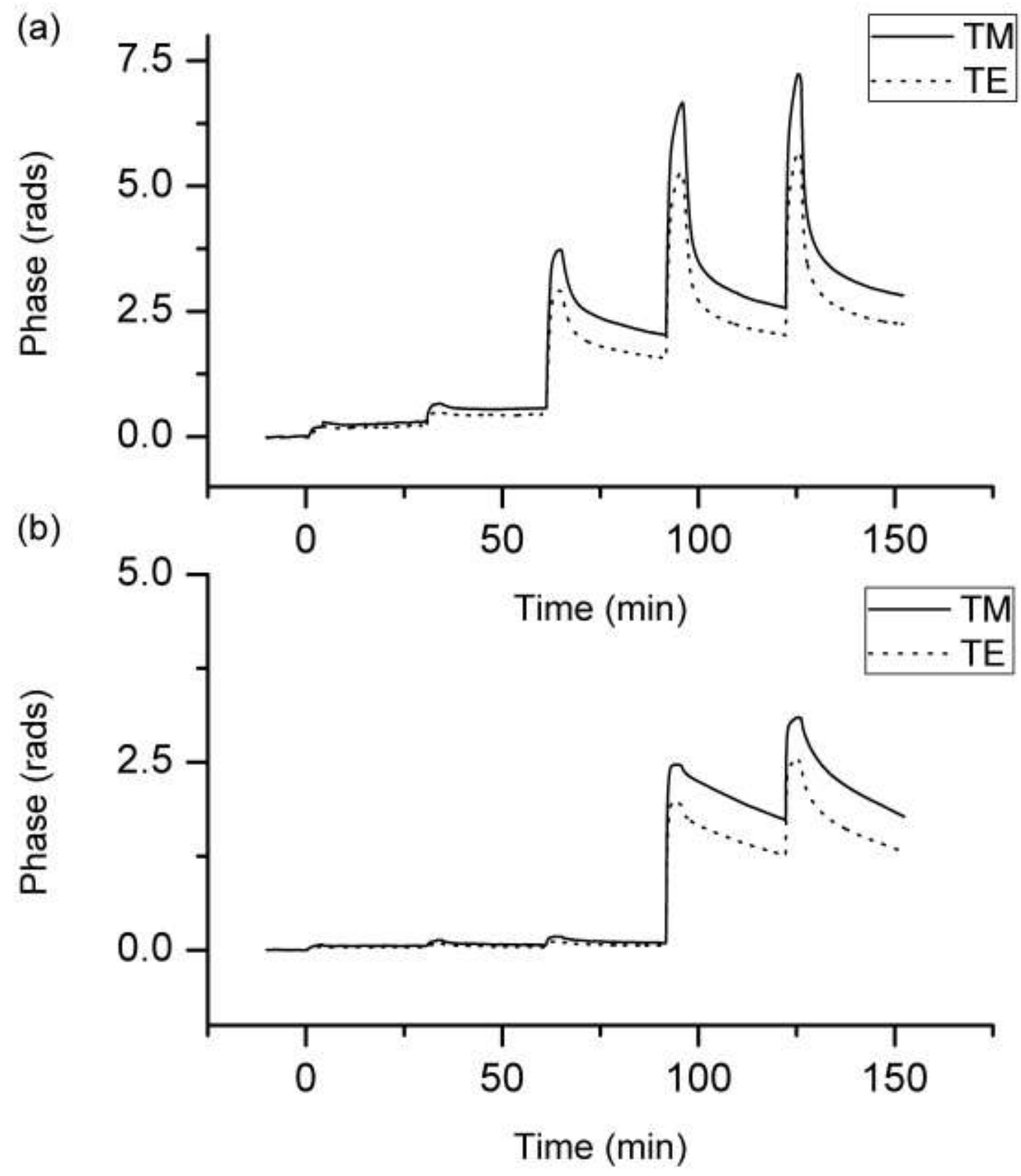

Figure 1. Real time $T_{M}$ and $T_{E}$ phase changes for consecutive injections of 1, 2, 5, 10 and 20 $\mu \mathrm{M}$ maculatin onto planar supported DMPC (top) and DMPC/DMPG (4:1) (bottom) bilayers. 
DMPC

(a)
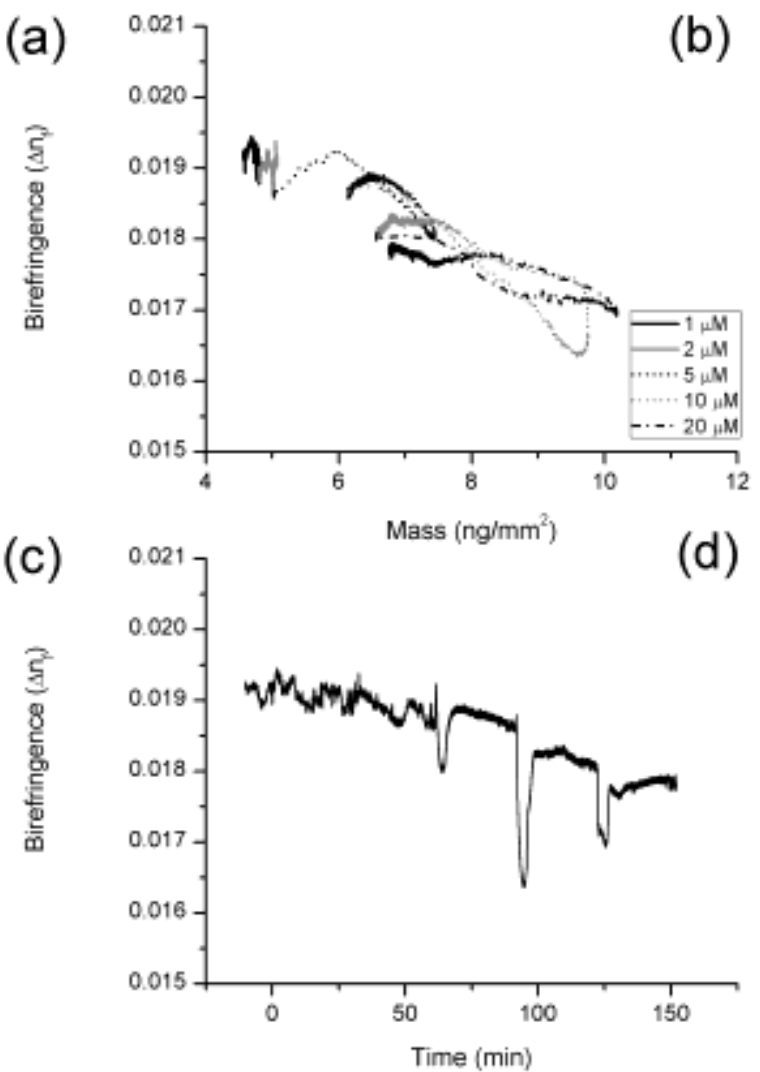

(e)

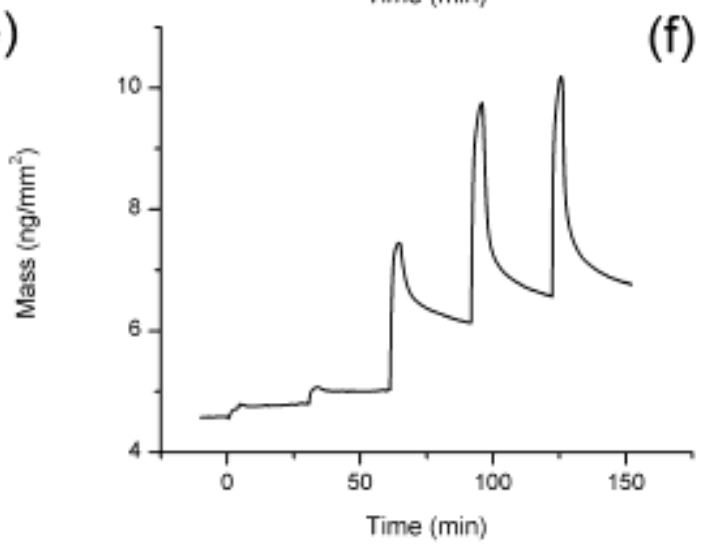

DMPC/DMPG

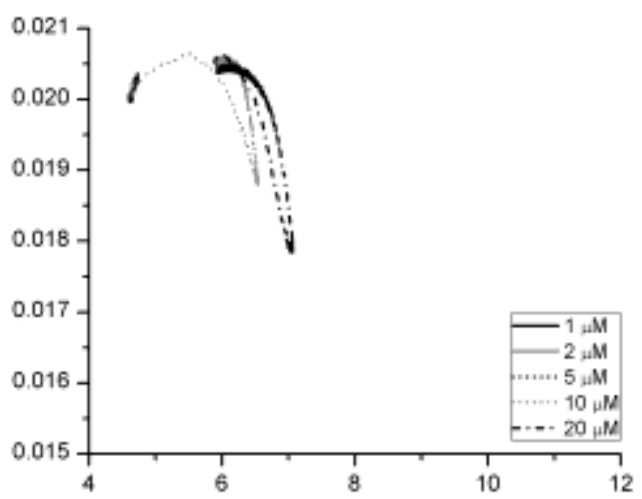

Mass (ng/mm $\left.{ }^{2}\right)$
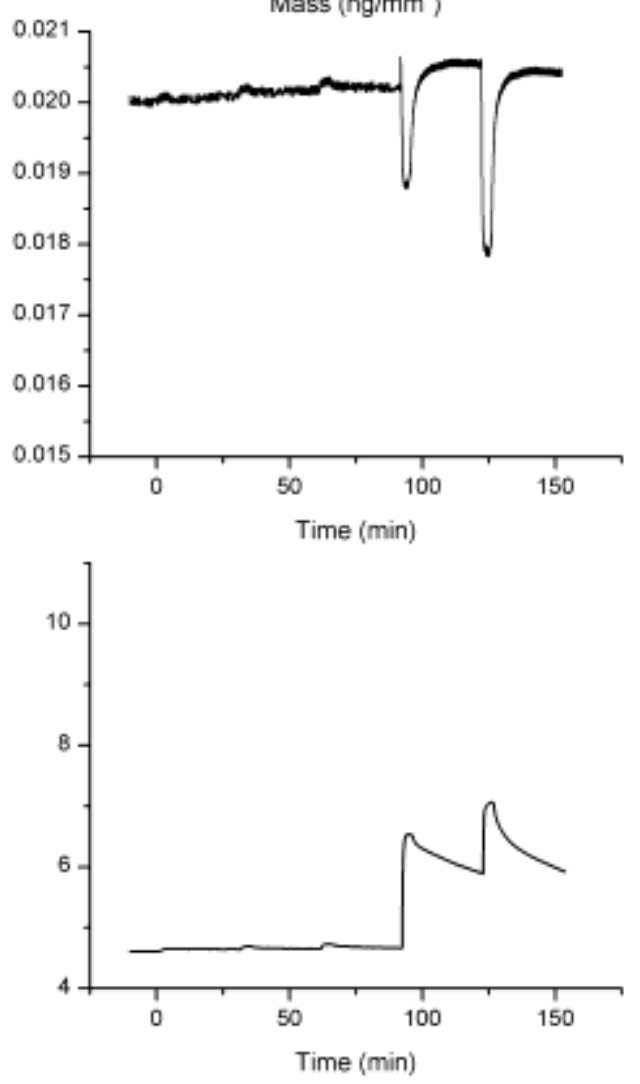

Figure 2. Measurements of mass and birefringence over time during consecutive injections of maculatin 1.1 onto planar supported DMPC (left) and 4:1 DMPC/DMPG (right) bilayers. Plots of birefringence vs. mass for injections of maculatin onto (a) DMPC and (b) DMPC/DMPG; birefringence vs. time for (c) DMPC and (d) DMPC/DMPG; mass vs. time for (e) DMPC and (f) DMPC/DMPG. For each plot, peptide was injected at time $=0$ (association phase) and after 4 min replaced by buffer solution for a period of $26 \mathrm{~min}$ (dissociation). Peptide was injected at increasing concentrations from 1 to $20 \mu \mathrm{M}$. 
a)

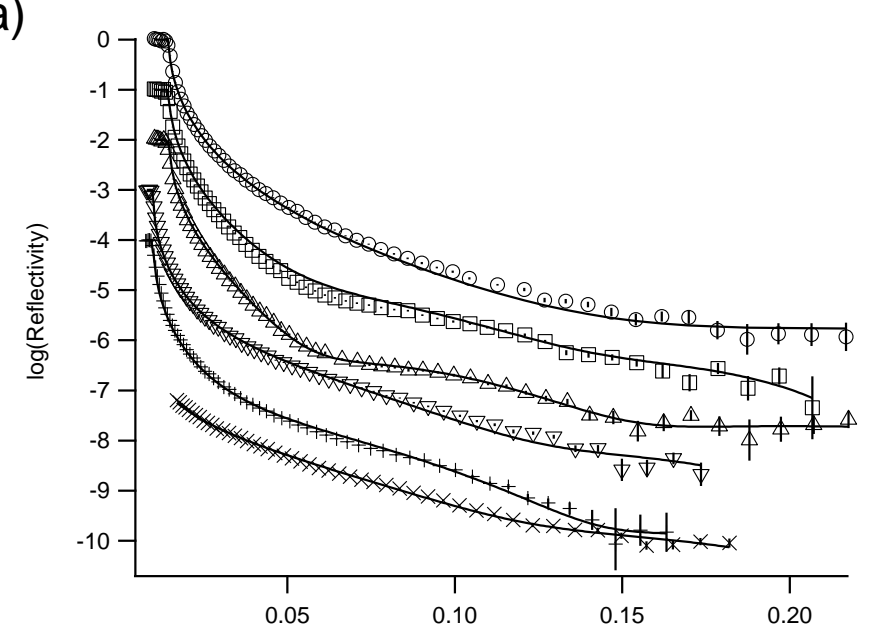

b)

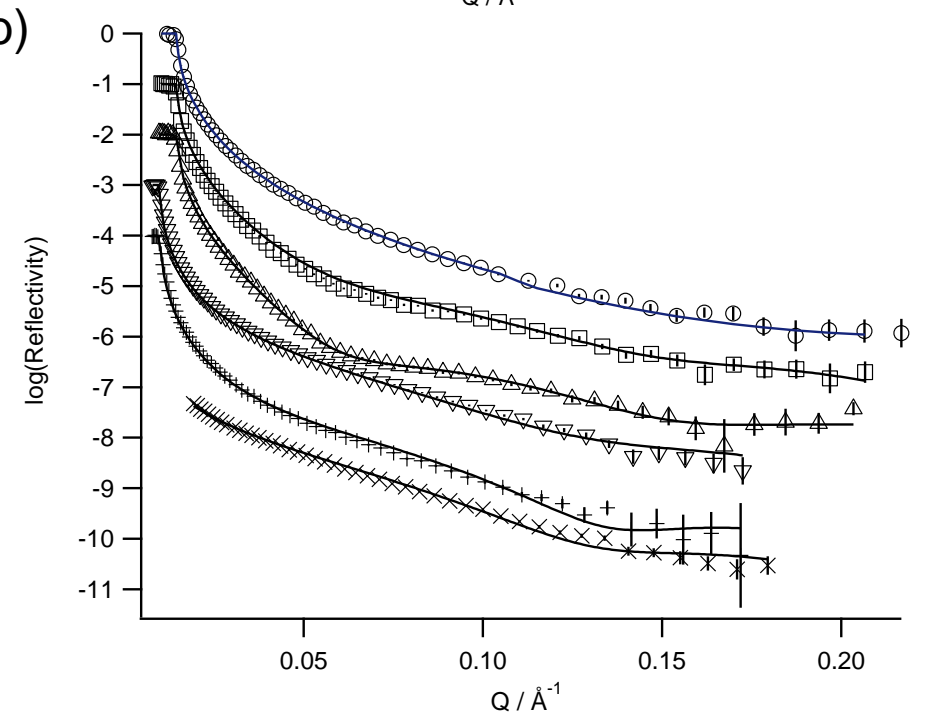

Figure 3. The reflectivity profiles of $\mathrm{D}_{2} \mathrm{O}$ against silica $(O)$, a bilayer on silica in $\mathrm{D}_{2} \mathrm{O}(\square)$ and the bilayer with maculatin 1.1 bound in $\mathrm{D}_{2} \mathrm{O}(\triangle)$, the bilayer on silica in CM4 $(\nabla)$, the bilayer with maculatin 1.1 bound in $\mathrm{CM} 4(+)$ and the bilayer with maculatin 1.1 bound in CMSi $(\times)$ for: a) the DMPC bilayer, and b) the mixed DMPC/DMPG (4:1) bilayer. The shapes with error bars are the collected data points and the lines are the model fits. The data sets are offset for clarity. 

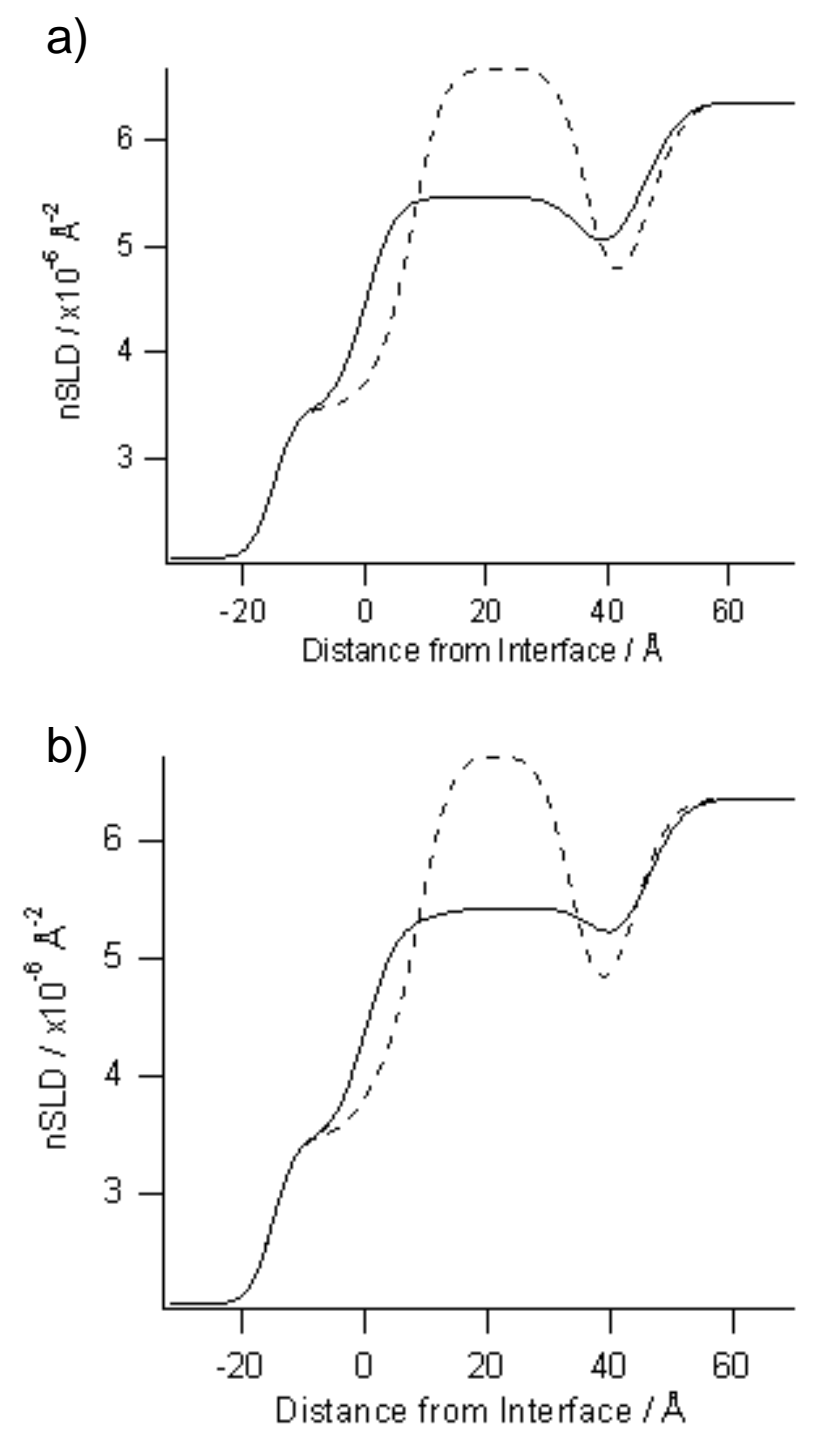

Figure 4. The real space scattering length density profiles of the phospholipid bilayers (dashed line) and with maculatin 1.1 bound (solid line) in a $\mathrm{D}_{2} \mathrm{O}$ subphase for a) the DMPC bilayer, and b) the mixed DMPC/DMPG bilayer. The distance from interface at $0 \AA$ is defined as the interface between the silicon oxide and head group 1. 


\section{University Library}

\section{- M M N E R VA A gateway to Melbourne's research publications}

Minerva Access is the Institutional Repository of The University of Melbourne

Author/s:

Fernandez, DI;Le Brun, AP;Lee, T-H;Bansal, P;Aguilar, M-I;James, M;Separovic, F

Title:

Structural effects of the antimicrobial peptide maculatin 1.1 on supported lipid bilayers

Date:

2013-01-01

Citation:

Fernandez, D. I., Le Brun, A. P., Lee, T. -H., Bansal, P., Aguilar, M. -I., James, M. \& Separovic, F. (2013). Structural effects of the antimicrobial peptide maculatin 1.1 on supported lipid bilayers. EUROPEAN BIOPHYSICS JOURNAL WITH BIOPHYSICS LETTERS, 42 (1), pp.47-59. https://doi.org/10.1007/s00249-012-0796-6.

Persistent Link:

http://hdl.handle.net/11343/282681 